Dear author,

Please note that changes made in the online proofing system will be added to the article before publication but are not reflected in this PDF.

We also ask that this file not be used for submitting corrections. 
ELSEVIER

\title{
Do you wish to waive your rights? Affect and decision-making in multilingual speakers
}

\author{
Aneta Pavlenko
}

This paper reviews recent developments in the study of multilingualism and affect, with the focus on two active areas: affective processing and decision-making. The converging pattern of findings suggests that foreign (FL) and second language (L2) processing do not engage affect to the same extent as processing in the first language (L1). This decreased reliance on affect has been linked to the systematic finding that speakers dealing with moral dilemmas and financial scenarios in a foreign language are less concerned about negative consequences and less averse to risk. This finding, termed the foreign language effect, may have important implications for language policies in multilingual contexts but first future studies need to link them conclusively to affective processing and identify mechanisms that give rise to these effects.

\section{Address}

Center for Multilingualism, University of Oslo, 7900C Stenton Ave Apt. Q2 309, Philadelphia, PA 19118, USA

Corresponding author: Pavlenko, Aneta (aneta.pavlenko@gmail.com)

\author{
Current Opinion in Psychology 2017, 17:xx-yy \\ This review comes from a themed issue on Emotion \\ Edited by Batja Gomes de Mesquita and Lisa Feldman Barrett
}

http://dx.doi.org/10.1016/j.copsyc.2017.06.005

2352-250X/C 2017 Elsevier Ltd. All rights reserved

On December 30, 2004, a Russian national, Natasha, a student in a US university, walked into the police precinct to be interviewed as a witness in a murder investigation. An hour into the English-language interview, she was read her Miranda Rights and asked if she wished to waive her rights and keep talking. The waiver, read in a casual monotone voice, was framed by the interrogating detective as a mundane bureaucratic procedure, used with everyone, and triggered neither fear nor even anxiety. Serene and unaware that her status had just changed from a witness to the suspect, Natasha waived her rights in what turned out to be the worst decision of her life [1]. In the traditional modular view of the mind, where language, emotions and decision-making are independent of each other, the only person to blame for this decision is Natasha herself. Language processing, in this view, is semantic processing, that is encoding and decoding of meanings, and a speaker who can hold a conversation in a second language (L2) should be able to compute the meaning of 'You have the right to remain silent' as 'You don't have to talk' and make an informed decision.

A growing body of research suggests, however, that there is more to language processing than computation of meanings - our interpretations are also sensitive to verbal and non-verbal cues and discursive framing and integrate affect and simulation of sensory-motor content: verbs like running, grabbing or throwing activate the same parts of the brain as direct physical actions they refer to and words that refer to emotional experiences activate neural structures involved in feeling the emotions in question [2-5]. These ground-breaking findings called for a reappraisal of the cognitive architecture of the human mind and became the cornerstone of a new approach that views cognition as situated and grounded, language as embodied, language processing as simulated action, language learning as a statistical process linked to frequency of experiences and word representations as clusters of experience [2,4-8]. This approach raises an interesting question with regard to multilingualism and emotions: if affective responses to words and phrases are a function of individual experiences, how do we process languages in which had few or no emotional experiences?

\section{Four facets of affective processing in bi- lingual and multilingual speakers}

Some words and phrases, like book, chair, or Come in, are fairly neutral, others, like kitten, hug, or I love you make us feel warm and fuzzy, and yet others, like homework, spider, or You have the right to remain silent, may trigger anxiety, aversion or fear. In psycholinguistic research, words and phrases that trigger positive or negative reactions are known as emotion-laden and emotional reactions to these words as affective processing. Note though that these terms, useful as shorthand, are also misleading because affect resides in speakers and hearers, not in words, and varies across speakers and situations: a diagnosis of Al:heimer's or cancer triggers a much more powerful reaction than experimental exposure to the same words. Nevertheless, laboratory studies show that some words and phrases, and in particular taboo and swearwords, do trigger affective responses as a function of previous experiences. The key question in studies with bi-linguals and multilinguals is whether these responses are triggered similarly in the L1 and the L2, a collective term for all languages learned later in life. The answer is not easy because bi-linguals and multilinguals are a heterogeneous population and affective processing consists of four sub-processes, two 
of which are cognitively oriented and the other two linked to embodiment.

The first subprocess involves assignment of affective valence, that is categorization of individual words and phrases as positive, negative or neutral. In the $\mathrm{L} 1$, this process is automatic but is it the same in the L2? This question is usually addressed through behavioral methods, such as lexical decision tasks (i.e. word/non-word), where congruent conditions (e.g. negative-negative) are expected to facilitate processing and lead to faster reaction times than non-congruent ones (e.g. negative-positive), an effect known as affective priming. In bilinguals, semantic priming (e.g. bread-baker) is observed in both languages, while affective priming is evident only in participants with high levels of immersion and frequency of L2 use [9,10]. A longitudinal study of adult L2 learners further found that learners begun extracting affective valence in the first weeks of L2 learning but the integration of semantic and affective processing did not occur until 6 months into their stay in the $\mathrm{L} 2$ context $\left[11^{\bullet \bullet}\right]$.

Yet we do not simply assign valence - we also prioritize words that elicit affect, extracting them faster than neutral words from the perceptual stream and holding on to them longer [12]. The process of perceptual prioritization has been examined through lexical decision tasks, event-related potentials (ERPs), and the Emotional Stroop task, where participants are asked to identify the print color of negative (e.g. shit in blue ink) and neutral (e.g. table in red ink) words, with the expectation that aversive words are harder to ignore and slow down the naming of color. The findings show that bilinguals process negative and positive words faster than neutral words [12,13] and display amplified early posterior negativity - interpreted as attention shift toward words with affective relevance - in both languages, with a time lag in the L2, which indicates reduced automaticity [14]. Bilinguals confronted with self-related stimuli also produced faster and more accurate responses in both languages, but the magnitude of the self-bias effect was significantly smaller in the L2 [15]. Several studies also identified a difference between negative and positive words, interpreted as positivity bias: positive words in the L2 display greater affective priming and are processed faster than other words $\left[11^{\bullet \bullet}, 12,16^{\bullet}\right]$. Negative L2 words, on the other hand, are easier to ignore, as seen in the Emotional Stroop task and ERP studies, where aversive words trigger interference only in the $\mathrm{L} 1\left[17^{\bullet}, 18,19,20^{\bullet}, 21\right]$.

Such stimuli may also elicit heightened autonomic arousal, whereby the brain upregulates the sympathetic nervous system, causing eccrine sweat glands to fill. Increased sweating, in turn, enhances electrical conductivity of the skin, also known as electrodermal reactivity, measured via fingertip electrodes. A transient increase in reactivity, following a presentation of a verbal stimulus is recorded as the skin conductance response (SCR) [22]. Studies with monolinguals show that aversive words (e.g. fuck) elicit higher SCRs than euphemisms (e.g. f-word) and neutral words [23]. In late bilinguals, SCRs and the overall skin conductance level (SCL) are higher in the L1, especially for taboo words and childhood reprimands, while in the L2 we do not sweat the small stuff, or at least not as much [22,24-26]. SCR, however, is not a perfect measure, since electrodermal reactivity can also be affected by other factors, ranging from room temperature (we sweat in response to heat) to anxiety associated with tests, lying or speaking in the less proficient language [25].

To deepen their understanding of embodiment researchers are beginning to examine emotion simulation in bilingual speakers. In one study, positive sentences, such as 'I am smiling', activated the zygomatic muscle involved in smiling in both languages, albeit with reduced magnitude in the L2, while the effect of negative sentences was limited to the $\left.\mathrm{L} 1{ }^{2} 7^{\circ}\right]$. In another, 'happy' passages from Harry Potter books in the L1 elicited stronger hemodynamic responses in bilateral amygdala and the left precentral cortex, associated with emotions [ $\left[8^{\bullet}\right]$.

Together, these findings show that automaticity of affective processing and the magnitude of effects in the L2 vary according to the type of stimuli (negative versus positive) and the subprocess in question. In the early stages, semantic processing is decoupled from the assignment of affective valence and somatovisceral responses. With the rise in the L2 proficiency and frequency of use, we see an increase in automaticity and integration of semantic and affective valence processing [9,11 $\left.{ }^{\bullet \bullet}\right]$ and perceptual prioritization $[12,13]$. In contrast, somatovisceral responses may remain more pronounced in the L1 [24,26].

The integration of all four subprocesses is modulated by the age and context of L2 acquisition, language dominance and contexts and frequency of L2 use: L2-dominant bilinguals display both perceptual prioritization and heightened autonomic arousal in the L2 [12,22]. These findings suggest that affective processing in multilingual speakers constitutes a continuum between the dominant L1 and foreign languages learned in the classroom. In between are languages learned later in life through daily use. The reason for diminished affective processing in the foreign language lies in the fact that language classrooms do not offer many opportunities for integration of word representations with autobiographic memories and sensory modalities - as a result, foreign languages are experienced as 'disembodied' [29-31]. The question asked in recent research is whether such disembodied processing could influence the decisions we make.

\section{Moral judgments and decision-making in the first and second language}

Decision-making is commonly influenced by affective reactions and in particular by anxiety, which tends to 
increase our aversion to risk. The reduced affective responses to aversive verbal stimuli in the L2 raised intriguing questions about the role of language in decision-making and moral judgment in bi-lingual and multilingual speakers. The paradigm-setting study by Keysar and associates [32 $2^{\bullet \bullet}$ ] used a task known as the Asian disease problem, where participants have to select one of two medicines to treat a disease and save lives. The choices are framed either in positive terms (e.g. 200 lives out of 600 will be saved) or in negative ones (e.g. 400 people out of 600 will die). The findings showed that the responses were significantly influenced by the language of the task. In the $\mathrm{L} 1$, the speakers displayed risk aversion in the context that emphasized gains (200 lives saved) and risk seeking in the context that emphasized losses (400 people will die). In the foreign language, this framing effect disappeared, with the disappearance explained through decreased reliance on affective processing - hence, the term the foreign language effect.

The foreign language effect in decision-making was then replicated by other researchers, with large and diverse groups of participants and a variety of tasks, lessening the likelihood of alternative explanations, such as cultural priming or differential processing costs $\left[33^{\bullet}, 34^{\bullet \bullet}, 35^{\bullet \bullet}, 36^{\bullet}, 37^{\bullet}, 38,39^{\bullet}, 40^{\bullet}, 41\right.$, but see 42,43$]$. One particularly popular task is a hypothetical, known as the Footbridge Dilemma, that involves a situation, where an on-coming train is about to kill five people. The only way to save them is to push a heavy man off the footbridge in front of the train but can you sacrifice one life to save five? Studies with multilinguals found that the utilitarian solution (kill one to save five) is selected significantly more frequently in the foreign language, with less proficient speakers making this choice more frequently $\left[33^{\bullet}, 34^{\bullet \bullet}, 37^{\bullet}, 42\right]$. In contrast, responses to non-moral and impersonal dilemmas (where one pushes a switch to kill a person) did not differ in the L1 and L2, nor did performance on logical problems $\left[33^{\bullet}, 34^{\bullet \bullet}, 35^{\bullet \bullet}, 37^{\bullet}, 40^{\bullet}, 42\right]$.

Moral judgment tasks also displayed the foreign language effect: bilinguals asked to judge moral transgressions provided more lenient evaluation in the L2 [36 $6^{\circ}$ and participants asked to rate hazards, such as climate change or traveling by airplane, judged the benefits higher and the risks lower in the L2 [39 $]$. In games of chance, positive feedback in the L 1 increased risk-taking behavior (the 'hot hand' effect), in contrast, participants who received positive feedback in the $\mathrm{L} 2$ responded slower and took fewer gambles; the differential neural processing of the two languages was also reflected in ERP components sensitive to emotional values [41]. This converging pattern of findings suggests that bilinguals are not always playing with a full deck in the L2 but what does this mean for our everyday lives?

\section{Implications and directions for future research}

The reduced negativity of the L2 may be an advantage in psychotherapy or trauma counseling, where we have to discuss traumatic events [29-31] but in situations that require detection of dangers and subtle threats, including police interviews, L2 speakers are at a significant disadvantage. Take the phrase 'You have the right to remain silent'. In native speakers of English, this phrase triggers a variety of negative associations: you are a suspect, you are under arrest, it is time to call an attorney. In contrast, Natasha, a native speaker of Russian and an international student in the USA, was unfamiliar with the Miranda rights and easily deceived by the framing of the waiver as a trivial bureaucratic document, signed by everyone [1]. Familiarity aside, if the waiver were administered to her in translation into her native Russian — whose terms would have had fuller impact — she may not have signed her rights away just as fast.

But before we draw implications for language policies, we need to move beyond task effects toward identification of mechanisms that give rise to these effects. To establish conclusive links between affective processing and decision-making the field needs more studies that combine behavioral, physiological and neuroimaging methods to understand the unfolding of affective processing in real time. To make recommendations for language policies, we also need more longitudinal studies attentive to different subprocesses and studies that emulate communicative situations. Most importantly, researchers need to pay more attention to distinct characteristics of their bilingual and multilingual participants. Most studies divide participants based on the age and context of L2 acquisition, proficiency, and frequency of L2 use. These variables are too generic to be of real use in the study of affective processing: some speakers who reside outside of the L2 context may have participated in emotional speech events through work on multilingual teams and others, who reside in the L2 context, may live their lives through the means of the L1. To identify context effects more precisely future research requires instruments sensitive to the type and quality of emotional experiences in the L2 [29,44]. In other words, what we really need to know to understand affective processing in bi-lingual and multilingual speakers is whether they had opportunities to joke, flirt, date, argue, and fight in the languages learned later in life.

\section{Conflict of interest statement}

Nothing declared.

\section{Acknowledgement}

This work was partly supported by the Research Council of Norway through $\quad 34323$ its Centres of Excellence funding scheme, project number 223265.

References and recommended reading

Papers of particular interest, published within the period of review, have been highlighted as: 
- of special interest
-. of outstanding interest

1. Pavlenko A: I'm very not about the law part": nonnative speakers of English and the Miranda Warnings. TESOL Q 2008 42:1-30.

2. Buccino G, Colagè I, Gobbi N, Bonaccorso G: Grounding meaning in experience: a broad perspective on embodied language. Neurosci Behav Rev 2016, 69:69-78.

3. Foroni F, Semin G: Comprehension of action negation involves inhibitory simulation. Front Hum Neurosci 2013, 7:209.

4. Moseley R, Shtyrov Y, Mohr B, Lombardo M, Baron-Cohen S, Pulvermüller F: Lost for emotion words: what motor and limbic brain activity reveals about autism and semantic theory. Neuroimage 2015, 104:413-422.

5. Kiefer M, Pulvermüller F: Conceptual representations in mind and brain: theoretical developments, current evidence and future directions. Cortex 2012:805-825.

6. Adams A: How language is embodied in bilinguals and children with specific language impairment. Front Psychol 2016, 7:1209.

7. Barsalou L: Grounded cognition. Annu Rev Psychol 2008, 59:617-645.

8. Bergen B: Louder Than Words: The New Science of How the Mind Makes Meaning. Basic Books; 2012.

9. Degner J, Doycheva C, Wentura D: It matters how much you talk: on the automaticity of affective connotations of first and second language words. Biling: Lang Cogn 2012, 15:181-189.

10. Segalowitz N, Trofimovich P, Gatbonton E, Sokolovskaya A: Feeling affect in a second language: the role of word recognition automaticity. Mental Lexicon 2008, 3:47-71.

11. Sianipar A, Middelburg R, Dijkstra T: When feelings arise with

- meanings: how emotion and meaning of a native language affect second language processing in adult learners. PLOS ONE 2015, 10:e0144576.

The first longitudinal study of development of affective processing in L2 learners. The combination of behavioral and ERP data suggests that semantic and affective processing in the L2 initially take place via separate channels. The eventual integration of the two processes is contingent on $\mathrm{L} 2$ exposure.

12. Kazanas S, Altarriba J: Emotion word processing: effects of word type and valence in Spanish-English bilinguals. $J$ Psycholing Res 2016, 45:395-406.

13. Ponari M, Rodríguez-Cuadrado S, Vinson D, Fox N, Costa A, Vigliocco G: Processing advantage for emotional words in bilingual speakers. Emotion 2015, 15:644-652.

14. Opitz B, Degner $\mathrm{J}$ : Emotionality in a second language: it is a matter of time. Neuropsychologia 2012, 50:1961-1967.

15. Ivaz L, Costa A, Dunabeitia J: The emotional impact of being myself: emotions and foreign-language processing. $J$ Exp Psychol: Learn Mem Cogn 2016, 42:489-496.

16. Sheikh N, Titone D: The embodiment of emotional words in a

16. Shecond language: an eye-movement study. Cogn Emot 2016, 30:488-500.

17. Colbeck K, Bowers J: Blinded by taboo words in L1 but not L2

- Emotion 2012, 12:217-222.

18. Fan L, Xu Q, Wang X, Zhang F, Yang Y, Liu X: Neural correlates of task-irrelevant first and second language emotion words evidence from the Emotional face-word Stroop task. Front Psychol 2016, 7:1672.

19. Winskel $\mathrm{H}$ : The Emotional Stroop task and emotionality rating of negative and neutral words in late Thai-English bilinguals. Int J Psychol 2013, 48:1090-1098.

20. Jończyk R, Boutonnet B, Musiał K, Hoemann K, Thierry G: The

- bilingual brain turns a blind eye to negative statements in the second language. Cogn Affect Behav Neurosci 2016, 16: $527-540$
21. Wu $Y$, Thierry G: How reading in a second language protects your heart. J Neurosci 2012, 32:6485-6489.

22. Harris C: Bilingual speakers in the lab: psychophysiological measures of emotional reactivity. J Multiling Multicult Dev 2004, 25:223-247.

23. Bowers J, Pleydell-Pearce C: Swearing, euphemisms, and linguistic relativity. PLOS ONE 2011, 6:e22341.

24. Harris C, Ayçiçegi A, Gleason J: Taboo words and reprimands elicit greater autonomic reactivity in a first language than in a second language. Appl Psycholing 2003, 24:561-571.

25. Caldwell-Harris $\mathrm{C}$, Aycicegi-Dinn A: Emotion and lying in a nonnative language. Int $J$ Psychophysiol 2009, 71:193-204.

26. Eilola T, Havelka J: Behavioral and physiological responses to the emotional and taboo Stroop tasks in native and non-native speakers of English. Int J Biling 2011, 15:353-369.

27. Foroni F: Do we embody second language? Evidence for

- 'partial' simulation during processing of a second language. Brain Cogn 2015, 99:8-16.

28. Hsu C, Jacobs A, Conrad M: Can Harry Potter still put a spell on

- us in a second language? An fMRI study on reading emotionladen literature in late bilinguals. Cortex 2015, 63:282-295.

29. Pavlenko A: Emotions and Multilingualism. Cambridge University Press; 2005.

30. Pavlenko A: Affective processing in bilingual speakers: disembodied cognition? Int J Psychol 2012, 47:405-428.

31. Pavlenko A: The Bilingual Mind and What it tells us about Language and Thought. Cambridge University Press; 2014.

32. Keysar B, Hayakawa S, An S: The foreign language effect:

- $\quad$ thinking in a foreign tongue reduces decision biases. Psychol Sci 2012, 23:661-668.

A ground-breaking study that first identified the foreign language effect. Using a variety of tasks, the researchers examined the influence of language on loss aversion preferences in several groups of foreign language speakers. The findings demonstrated that in the L1, participants displayed risk aversion in the context that emphasized gains and risk seeking in the context that emphasized losses (400 people will die). In the foreign language, the framing effect disappeared. This disappearance was attributed to decreased reliance on affective processing.

33. Cipolletti $\mathrm{H}$, McFarlane S, Weissglass $\mathrm{C}$ : The moral foreign-

- language effect. Philos Psychol 2016, 29:23-40.

34. Costa A, Foucart A, Hayakawa S, Aparici M, Apesteguia J,

-• Heafner J, Keysar B: Your morals depend on language. PLOS ONE 2014, 9:e94842.

The study replicated the foreign language effect and highlighted performance differences on personal and impersonal moral dilemmas, as well as differences between more and less proficient foreign language speakers.

35. Costa A, Foucart A, Arnon I, Aparici M, Apesteguia J: "Piensa"

-. twice: on the foreign language effect in decision-making. Cognition 2014, 130:236-254.

Deepening the understanding of the foreign language effect, the study also decreased the likelihood of alternative explanations by showing that the effect is limited to personal moral dilemmas, while answers to unemotional logical problems did not vary by language.

36. Geipel J, Hadjichristidis C, Surian L: How foreign language

- $\quad$ shapes moral judgment. J Exp Soc Psychol 2015, 59:8-17.

37. Geipel $J$, Hadjichristidis $C$, Surian $L$ : The foreign language effect

- $\quad$ on moral judgment: the role of emotions and norms. PLOS ONE 2015, 10:e0131529.

38. Geipel J, Hadjichristidis C, Surian L: Foreign language affects the contribution of intentions and outcomes to moral judgment. Cognition 2016, 154:34-39.

39. Hadjichristidis C, Geipel J, Savadori L: The effect of foreign

- language in judgments of risk and benefit: the role of affect. $J$ Exp Psychol: Appl 2015, 21:117-129.

40. Winskel H, Ratitamkul T, Brambley V, Nagarachinda T,

- Tiencharoen S: Decision-making and the framing effect in a foreign and native language. $J$ Cogn Psychol 2016, 28:427-436. 
41. Gao S, Zika O, Rogers R, Thierry G: Second language feedback abolishes the "hot hand" effect during even-probability gambling. J Neurosci 2015, 35:5983-5989.

42. Chan $\mathrm{Y}, \mathrm{Gu} X, \mathrm{Ng} \mathrm{J}$, Tse C: Effects of dilemma type, language and emotion arousal on utilitarian versus deontological choice to moral dilemmas in Chinese-English bilinguals. Asian J Soc Psychol 2016, 19:55-65.
43. Oganian $\mathrm{Y}$, Korn $\mathrm{C}$, Heekeren $\mathrm{H}$ : Language switching - but not foreign language use per se - reduces the framing effect. $J$ Exp Psychol: Learn Mem Cogn 2016, 42:140-148.

44. Dewaele JM: Emotions in Multiple Languages. Palgrave Macmillan; 2010. 